\title{
Outcomes of left internal mammary artery with saphenous vein composite graft to bypass the left anterior descending artery: a propensity-matched study
}

\author{
Dongjie $\mathrm{Li}^{1}$, Song Gu${ }^{1}$, Yan Liu ${ }^{1}$, Xitao Zhang ${ }^{1}$, Xiangguang An ${ }^{1}$, Jun Yan ${ }^{1}$, Hong Wang ${ }^{2}$, Yulin Guo \\ Pixiong $\mathrm{Su}^{1}$ \\ ${ }^{1}$ Department of Cardiac Surgery, Heart Center, Chaoyang Hospital, Capital Medical University, Beijing, China; ${ }^{2}$ Center for Cardiac Intensive Care, \\ Beijing Institute of Heart, Lung, and Blood Vessel Diseases, Beijing Anzhen Hospital, Capital Medical University, Beijing, China \\ Contributions: (I) Conception and design: D Li, H Wang, P Su; (II) Administrative support: Y Liu, X Zhang, J Yan, P Su; (III) Provision of study \\ materials or patients: D Li, X An, P Su; (IV) Collection and assembly of data: D Li, Y Guo; (V) Data analysis and interpretation: D Li, S Gu, Y Guo, \\ P Su; (VI) Manuscript writing: All authors; (VII) Final approval of manuscript: All authors. \\ Correspondence to: Pixiong Su, MD. Department of Cardiac Surgery, Heart Center, Chaoyang Hospital, Capital Medical University, no. 8 Gong Ti \\ South Road, Chaoyang District, Beijing 100020, China. Email: supixiong1130@163.com.
}

\begin{abstract}
Background: This study aimed to evaluate the early and mid-term outcomes of a novel strategy of using the in-situ left internal mammary artery (LIMA) with the great saphenous vein graft (SVG) to bypass the left anterior descending artery (LAD) in coronary artery bypass grafting (CABG).

Methods: A total of 979 patients took part in this retrospective observational study; 83 patients were propensity-score matched to the LIMA + SVG group and 83 to the LIMA - LAD group. Early mortality, postoperative complications, mid-term major adverse cardiovascular and cerebrovascular events (MACCE) were compared among the two matched groups after the procedure.

Results: No significant differences in early mortality and postoperative complications rates were detected between the two matched groups. For mid-term outcomes, the incidence of MACCE was slightly higher in the LIMA + SVG group, but there was no significant statistical difference $(14.9 \%$ vs. $12.8 \%$, hazard ratio $=1.20,95 \% \mathrm{CI}, 0.24$ to $7.95 ; \mathrm{P}=0.70)$ between the matched groups. Computed tomography coronary artery angiography (CTCA) images showed a LIMA + SVG composite graft patency rate of 94\% (32/34) 25 months after the procedure.

Conclusions: Using the in situ LIMA with SVG to revascularize LAD was associated with comparable early and mid-term outcomes. These findings may provide an alternative emergency strategy when in situ LIMA cannot bypass LAD. Further study needs to be conducted to test longer-term outcomes.
\end{abstract}

Keywords: Coronary artery bypass grafting (CABG); left internal mammary artery (LIMA); great saphenous vein graft; composite graft; major adverse cardiovascular and cerebrovascular events (MACCE)

Submitted Jul 03, 2020. Accepted for publication Sep 30, 2020.

doi: $10.21037 /$ jtd-20-2358

View this article at: http://dx.doi.org/10.21037/jtd-20-2358

\section{Introduction}

The choice of conduits to bypass target vessels has been a perennial topic of debate since left internal mammary artery (LIMA) anastomosed to the left anterior descending artery (LAD) became the gold standard by virtue of its superior long-term outcomes and patency (1-4). However, the in situ LIMA is occasionally unavailable or unsuitable as a bypass conduit to LAD, when, for instance, there is a relatively shorter LIMA due to the enlargement of left ventricular, difficulty in harvesting the proximal LIMA, accidental injury of the LIMA pedicle during harvesting (5), calcification of the middle or distal LIMA, or mismatching 
between the LAD and slight distal LIMA.

As a solution to this, Vistarini et al. (5) have proposed using free internal mammary artery (IMA) grafts to bypass the LAD for a substitution of the in situ LIMA. However, considering that there is a higher risk of developing deep sternal infection when bilateral internal mammary arteries (BIMAs) are harvested with pedicle grafts, especially for older patients with diabetes (6-9), surgeons usually use the in situ LIMA procedure as often as possible to avoid the risk of the sternal infection in diabetic patients using the BIMAs. A superior patency rate can also be achieved from using the great saphenous vein graft (SVG) to bypass the LAD when compared with other regions (2). Thus, at our center, we performed an end-to-end anastomosis with the distal in situ LIMA and a length of SVG (LIMA + SVG) to establish a composite graft to bypass the LAD.

In two retrospective studies of Tremblay et al. (10) and Kim et al. (11), the researchers established similar composite grafts for bypassing the LAD segment, which also included our method of using LIMA + SVG. However, both strategies were sequential or Y-grafts, the venous conduit was used to revascularize the lateral and inferior wall, and there was not enough data reported concerning the outcomes of using LIMA + SVG to bypass the LAD.

This study thus aimed to test the effectiveness of our method of using LIMA + SVG for bypassing the LAD. We evaluated the early and midterm clinical outcomes of this surgical strategy and compared them to those of standard LIMA to LAD anastomosing. We present the following article in accordance with the STROBE reporting checklist (available at http://dx.doi.org/10.21037/jtd-20-2358).

\section{Methods}

\section{Study population}

This was a single-center, retrospective cohort study conducted at Beijing Chaoyang Hospital, Capital Medical University. Between January 2014 and January 2018, 1016 consecutive patients underwent isolated coronary artery bypass grafting (CABG) at Chaoyang Hospital. The study was conducted in accordance with the Declaration of Helsinki (as revised in 2013). The study was approved by local research ethics board of Chaoyang Hospital (No.: 2018308) and individual consent for this retrospective analysis was waived. Any individual undergoing emergency operations, SVG-LAD anastomosis, free IMA to $\mathrm{LAD}$ anastomosis, preoperative dialysis, and hemodynamic instability were excluded. Finally, 979 patients took part in this study; among these patients, 83 underwent a LIMA + SVG graft to LAD anastomosis, and 896 underwent a conventional LIMA to LAD anastomosis. Preoperative, intraoperative, and postoperative data were retrospectively extracted from the electronic medical record of Chaoyang Hospital. The study was approved by local research ethics board of Chaoyang Hospital and individual consent for this retrospective analysis was waived. Variables available in the registry, including demographics, patient history, preoperative risk factors, and intraoperative data, along with in-hospital, 30-day, and mid-term outcomes were defined according to the Society of Thoracic Surgeons database and the 2013 "ACCF/AHA Key Data Elements and Definitions for Measuring the Clinical Management and Outcomes of Patients with Acute Coronary Syndromes and Coronary Artery Disease" (12). According to Sianos's description (13), SYNTAX score was completed by three interventional physicians who were not involved in the project design and data analysis. Preoperative data of patients were collected to calculate the EuroSCORE II. After the 1:1 propensity score matching of the patients, 83 patients were enrolled in the LIMA + SVG group and 83 patients were enrolled in the LIMA - LAD group.

\section{Surgical technique}

The same experienced surgeon performed all surgical procedures (PXSu); the LIMA to LAD anastomosis procedures have been described previously (14). Standard procedures were followed according to established protocols (15). The LIMA is harvested as a pedicle. According to the operative record, the specific reasons for the unavailability of the in situ LIMA were the following: a relatively shorter LIMA due to left ventricular enlargement $(n=21)$, difficulty harvesting the LIMA ( $n=12)$, accidental injury to the LIMA pedicle during its harvesting $(\mathrm{n}=23)$, significant calcification of the middle or distal LIMA causing restriction to blood flow ( $\mathrm{n}=18)$, or mismatching between the LAD and slight distal LIMA ( $n=9)$. According to surgical experience, a decision would be made to cut off the unavailable part of the in situ LIMA, and a length of SVG (mean length of $3.9 \pm 1.8 \mathrm{~cm}$ ) would be end-to-end anastomosed at the distal end of the LIMA to form a composite graft to bypass the LAD (Figure 1). All the SVGs were harvested via endoscope and skeletonized. Next, we chose the SVG of the distal end of the lower leg and reduced distension to guarantee diameter matching with the LIMA and LAD. Transit-time 


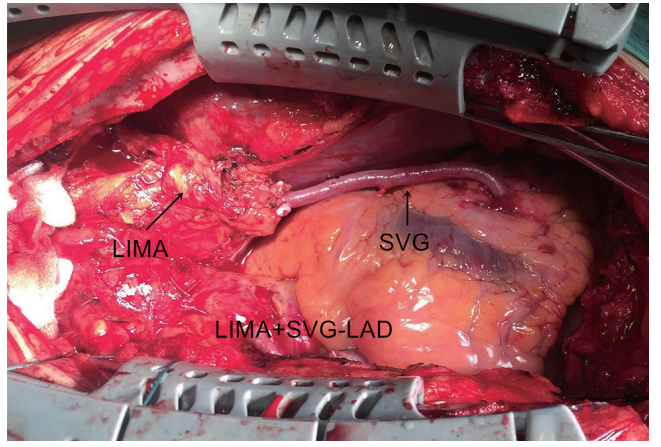

Figure 1 Surgical procedure. LIMA + SVG was end-to-end anastomosed to build a composite graft to bypass the LAD. LIMA, left internal mammary artery; SVG, great saphenous vein graft; $\mathrm{LAD}$, left anterior descending artery.

flow measurement (TTFM) was used to examine the flow of grafts after all the anastomoses were completed.

\section{Follow-up}

The standardized postoperative management and followup procedures we used have been described previously (14). After surgery, all patients in both groups were treated with the secondary prophylactic medication if there were no contraindications. Aspirin was administered within 6 hours after CABG in doses of $100 \mathrm{mg}$ daily for a life time. Dual antiplatelet was administered for 1 year with combined aspirin $100 \mathrm{mg}$ daily and clopidogrel $75 \mathrm{mg}$ daily. Warfarin was not routinely prescribed after CABG for graft patency unless patients had other indications for long-term antithrombotic therapy. Following institutional standard procedures, all patients were required to return to the clinic for a postoperative follow-up at 1 and 6 months after surgery, and then once a year after that. The outpatient clinic records of patients who reported having any adverse events were evaluated further for confirmation. If other hospitals encountered any major clinical events, patients were requested to provide a copy of all related medical information to the researcher for further assessment. Otherwise, patients who did not return for follow-up visits were contacted by telephone during the data review period using standard procedures and follow-up visit forms. For further diagnosis, routine computed tomography coronary artery angiography (CTCA) was also offered to patients in the LIMA + SVG group 2 years after the procedure, and a standard coronary angiogram was carried out when necessary for both groups. Two radiologists evaluated grafts, and the graft was defined as a patent if the stenosis was less than $50 \%$ on their follow-up angiography. The primary outcome was mid-term major adverse cardiovascular and cerebrovascular events (MACCE) after the procedure, including death, myocardial infarction (MI), cerebrovascular accidents (CVA) or stroke, and repeat revascularization. The secondary outcome was mid-term all-cause mortality.

\section{Statistical analysis}

A 1:1 propensity score matching was performed using a logistic regression model to reduce the impact of selection bias and potential confounding variables for this observational study. The variables of all patients' demographic and clinical risk factors included in the logistic regression analysis were age, female, hypertension, diabetes mellitus, chronic obstructive pulmonary disease, body mass index, left ventricular ejection fraction (LVEF), left ventricular end-diastolic dimensions, peripheral vascular disease, acute coronary syndrome, creatinine level, left main stenosis, previous MI, previous percutaneous coronary intervention (PCI), and previous stroke (Table 1).

Matching was performed using greedy, nearest neighbor matching with calipers of width 0.1 standard deviations of the logit of the propensity score. The standardized differences were used to assess the balance for all the baseline covariates before and after matching. Standardized differences of less than $10 \%$ indicated intergroup equilibrium (16). The standardized differences were calculated via $R$ version 2.15.3.

The measurement data are expressed as mean and standard deviation, and the counting data are expressed as a proportion. Comparisons of the characteristics between the LIMA - LAD group and LIMA + SVG group were assessed by $t$-test or Mann-Whitney $\mathrm{U}$ test for continuous variables and the chi-square test or Fisher exact test for categorical variables before and after matching. The follow-up time was determined from the date of operation to when all patient information was censored at the last observed follow-up date. The incidence of all-cause death and MACCE between the two groups during follow-up is expressed as Kaplan-Meier survival curves. Mid-term outcomes are presented as hazard ratios associated with 95\% confidence intervals (CIs) from the Cox regression model. The statistical data analysis was performed by SPSS (IBM Corp. Released 2013. IBM SPSS Statistics for Windows, Version 22.0. Armonk, NY, USA). All the matching procedures were performed via $\mathrm{R}$ version 2.15.3. A $P$ value $<0.05$ was considered statistically significant. 
Table 1 Preoperative characteristics of unmatched and matched patients

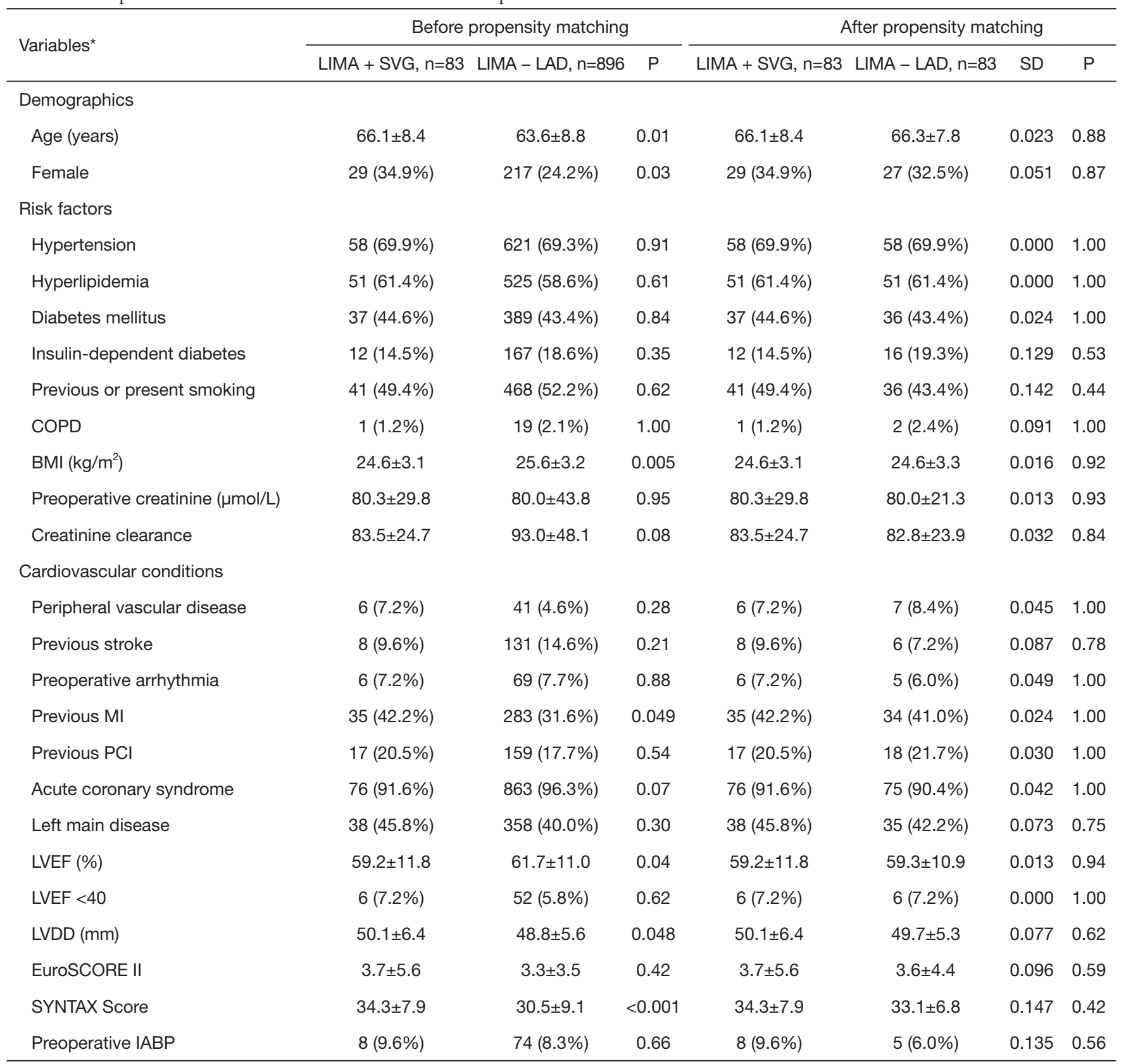

*, continuous variables with normal distribution are presented as mean \pm SD unless otherwise noted. LIMA + SVG, left internal mammary artery + great saphenous vein; LIMA - LAD, left internal mammary artery-left anterior descending artery; SD, standardized difference; COPD, chronic obstructive pulmonary disease; BMI, body mass index; MI, myocardial infarction; PCI, percutaneous coronary intervention; LVEF, left ventricular ejection fraction; LVDD, left ventricular end-diastolic dimension; IABP, intra-aortic balloon pump.

\section{Results}

\section{Baseline characteristics and early outcomes}

We selected 979 patients who met our inclusion criteria, of whom $83(8.5 \%)$ underwent LIMA + SVG to LAD anastomosis, and 893 (91.5\%) underwent LIMA to LAD anastomosis. There were significant differences in the demographics and comorbidities of the patients before propensity-score matching. For the unmatched population, patients in the LIMA + SVG group had older ages 
Table 2 Intraoperative characteristics and 30-day outcomes of matched patients

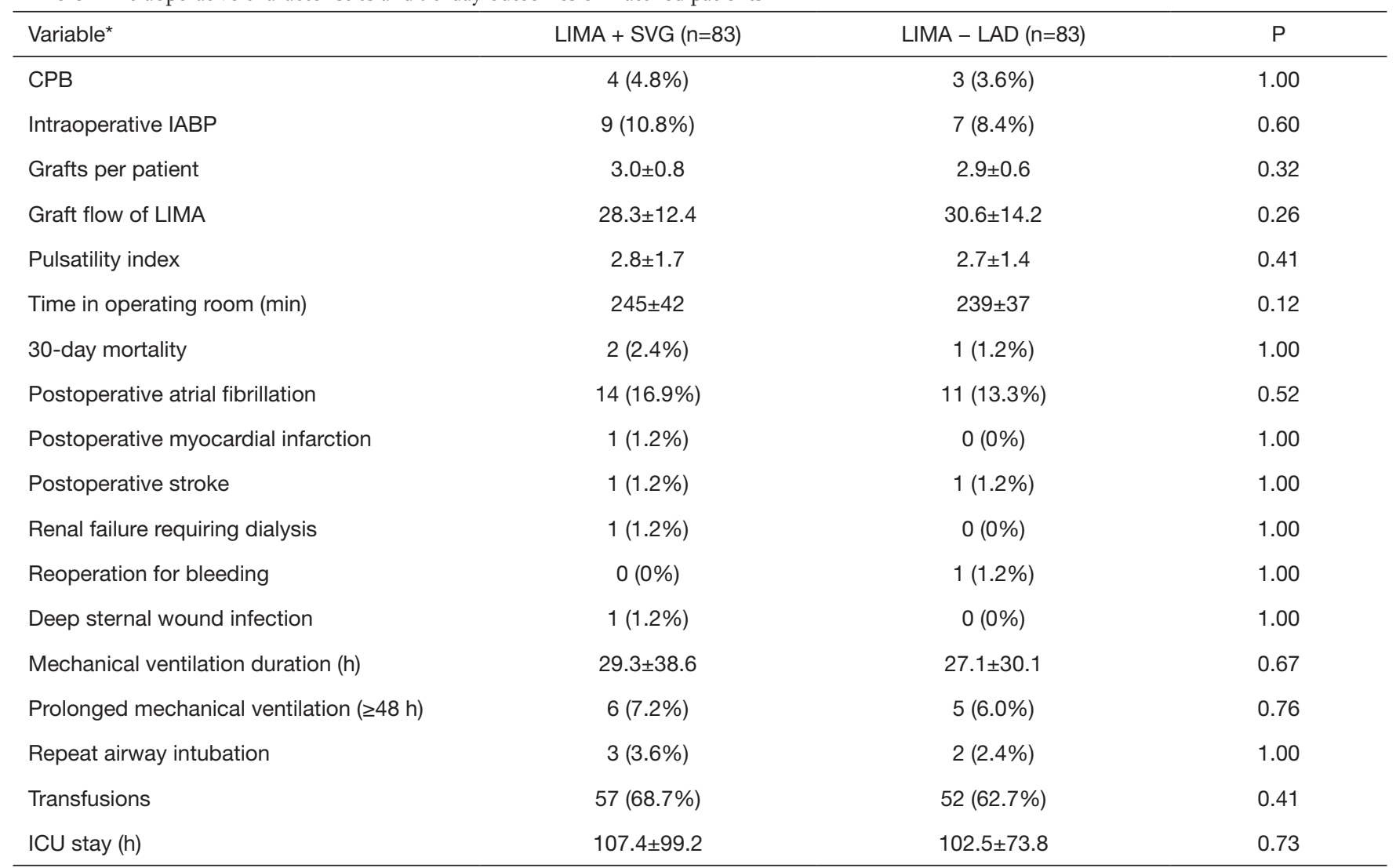

*, continuous variables with normal distribution are presented as mean \pm SD unless otherwise noted. LIMA + SVG, left internal mammary artery + great saphenous vein; LIMA - LAD, left internal mammary artery-left anterior descending artery; CPB, cardiopulmonary bypass; IABP, intra-aortic balloon pump; LIMA, left internal mammary artery; ICU, intensive care unit.

statistically, a higher proportion of female patients, previous MI, and lower BMI. Also, there were significantly lower left ventricular ejection fraction (LVEF), more left ventricular impairment, and more severe coronary lesions in the LIMA + SVG group (Table 1).

After a 1:1 matching, 83 patients in the LIMA + SVG group were matched with 83 patients in the LIMA - LAD group. No differences in preoperative variables were found between the two groups. The standardized differences of all the matched covariates were lower than 0.1 , showing an excellent match between the two groups (Table 1).

Intraoperative characteristics and 30-day outcomes of the matched patients are detailed in Table 2. There were four patients in the LIMA + SVG group, and three in the LIMA - LAD group who underwent on-pump beating-heart CABG. There were no statistically significant differences in the number of distal anastomoses, use of intraoperative intraaortic balloon pump (IABP), LIMA graft flow, pulsatility index (PI) and time spent in the operating room between the two matched groups. The LIMA + SVG group (2, 2.4\%) had a slightly higher 30-day mortality than the LIMA - LAD group $(1,1.2 \%)$, although this was not statistically significant $(\mathrm{P}=1.00)$. The causes of early mortality were perioperative $\mathrm{MI}$ associated with right coronary and stroke in the LIMA + SVG group and ventricular fibrillation in the LIMA - LAD group. It is difficult to determine whether the ventricular fibrillation was related to LIMA. Postoperative renal failure requiring dialysis, atrial fibrillation, MI, stroke, reoperation for bleeding, deep sternal wound infection, mechanical ventilation duration, prolonged mechanical ventilation, repeat airway intubation, transfusions, and ICU stay were comparable between the two groups.

\section{Mid-term outcomes}

Both groups completed follow-up, and the mean follow-up 
A

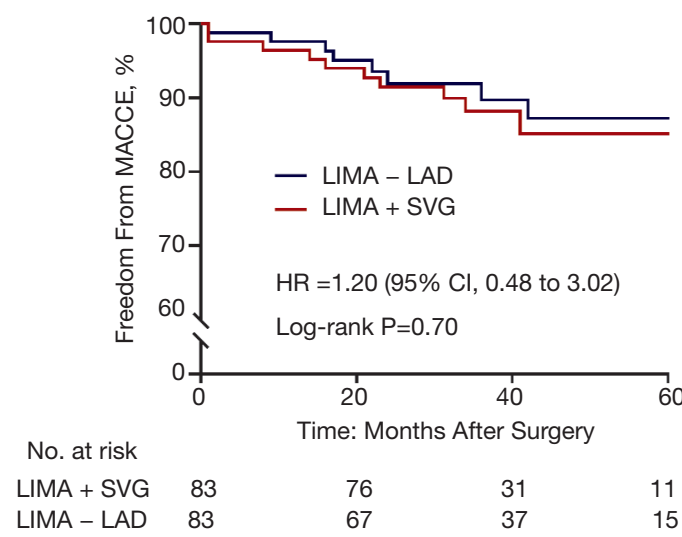

B

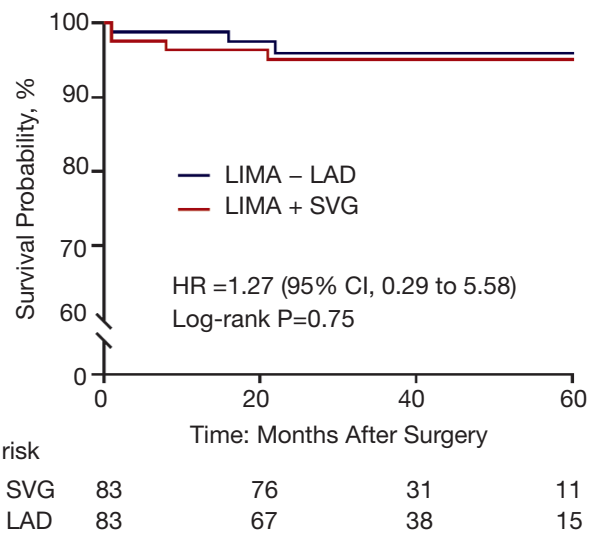

Figure 2 Kaplan-Meier cumulative mid-term outcomes after surgery. Kaplan-Meier survival curves show freedom from MACCE (A) and mid-term survival probability (B) in the LIMA + SVG group (red line) and LIMA - LAD group (blue line) after propensity-score matching. MACCE, major adverse cardiovascular and cerebrovascular events; LIMA, left internal mammary artery; SVG, great saphenous vein graft; $\mathrm{LAD}$, left anterior descending artery.

Table 3 Mid-term outcomes between matched LIMA + SVG and LIMA - LAD

\begin{tabular}{|c|c|c|c|c|}
\hline Outcomes* & LIMA + SVG, $(n=83)$ & LIMA - LAD, $(n=83)$ & $\mathrm{HR}(95 \% \mathrm{Cl})$ & $\mathrm{P}$ \\
\hline All cause death & $4(4.9 \%)$ & $3(4.1 \%)$ & 1.27 (0.29 to 5.58$)$ & 0.75 \\
\hline Myocardial infarction & $3(4.4 \%)$ & $2(4.0 \%)$ & 1.52 (0.26 to 8.76$)$ & 0.64 \\
\hline Stroke & $2(2.9 \%)$ & $3(4.8 \%)$ & 0.64 (0.11 to 3.70$)$ & 0.62 \\
\hline MACCE & $10(14.9 \%)$ & $8(12.8 \%)$ & 1.20 (0.24 to 7.95$)$ & 0.70 \\
\hline
\end{tabular}

*, continuous variables with normal distribution are presented as mean \pm SD unless otherwise noted. LIMA + SVG, left internal mammary artery + great saphenous vein; LIMA - LAD, left internal mammary artery-left anterior descending artery; $\mathrm{HR}$, hazard ratio; Cl, confidence intervals; MACCE, major adverse cardiovascular and cerebrovascular events.

time was $38.5 \pm 14.3$ and $40.5 \pm 20.4$ months in the LIMA + SVG and LIMA - LAD groups respectively, which was not a statistically significant difference $(\mathrm{P}=0.46)$.

There were four patients in the LIMA + SVG group and three patients in the LIMA - LAD group who died during the entire span of the study period. All deaths were caused by cardiovascular events, except for one patient in the LIMA + SVG group and one patient in the LIMA - LAD group who died of cerebral infarction and renal failure, respectively. For the five cardiac deaths, two were MIs and one was heart failure in the LIMA + SVG group, while one was ventricular fibrillation and one was MI in the LIMA - LAD group. After propensity matching, Kaplan-Meier survival curves showed the estimated mid-term survival rates were $95.1 \%$ in the LIMA + SVG group and $95.9 \%$ in the LIMA - LAD group. According to a univariate Coxregression model, there were no statistically significant differences in mid-term survival between the matched patients during the follow-up period (hazard ratio $=1.27$, 95\% CI, 0.29 to 5.58; $\mathrm{P}=0.75$ ) (Figure 2). Neither mid-term MI, stroke, nor repeat revascularization between the two groups reached statistical significance (Table 3). Finally, the estimated 5-year risk of freedom from MACCEs was lower in the LIMA + SVG group (85.1\%) than in the LIMA LAD group $(87.2 \%)$ (Figure 2). However, there were no significant differences between the two matched groups (hazard ratio $=1.20,95 \% \mathrm{CI}, 0.24$ to $7.95 ; \mathrm{P}=0.70$ ) (Table 3).

According to doctor advice and patient desires, 34 


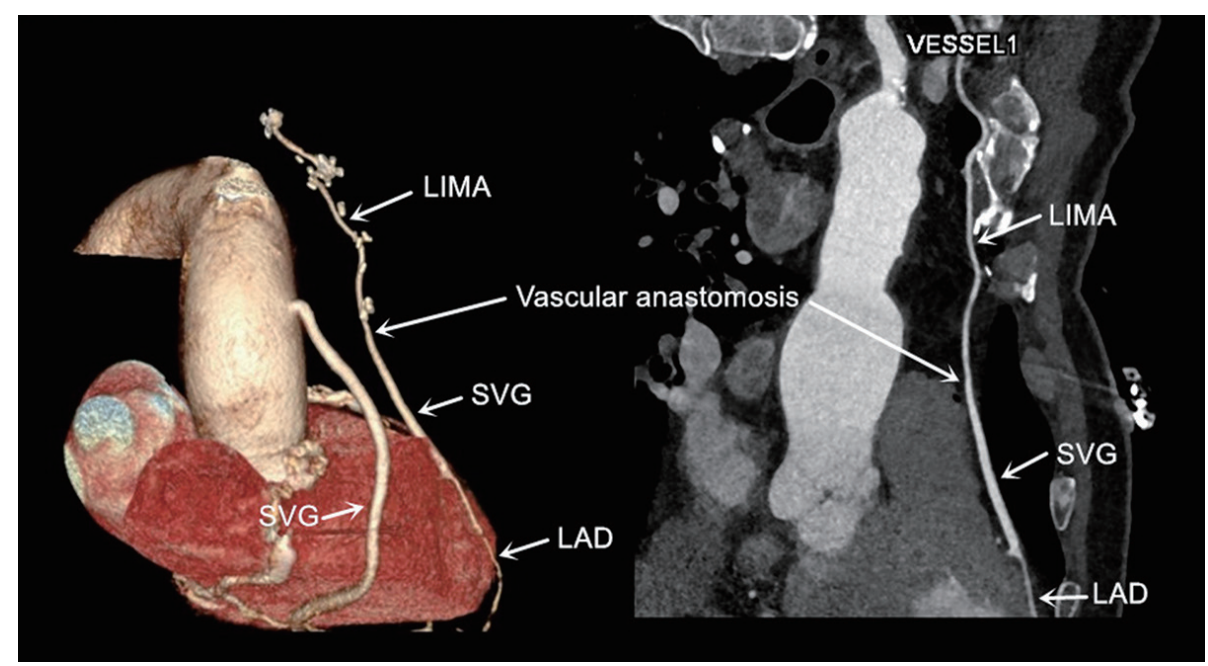

Figure 3 CTCA images of LIMA + SVG-LAD graft. CTCA images show a patent LIMA + SVG-LAD graft 27 months after surgery, with the two sides of the SVG being well matched with in situ LIMA and LAD, respectively. CTCA, computed tomography coronary artery angiography; LIMA, the left internal mammary artery; SVG, great saphenous vein graft; LAD, left anterior descending artery.

(41\%) patients underwent routine CTCA with a mean observational time of 25 months (23-27 months) after the procedure in the LIMA + SVG group. All $(100 \%)$ of the 96 grafts were assessed; of the 34 LIMA + SVG segments, $32 / 34(94 \%)$ were patent, 1 graft had $70 \%$ stenosis at the anastomosis of LIMA and SVG, and 1 LIMA + SVG graft was occluded on follow-up CTCA images. Of the 62 aortocoronary SVG grafts, 52/62 (84\%) were patent (Figure 3).

In addition, three patients in the LIMA + SVG group and two patients in the LIMA - LAD group had symptom-driven cardiac catheterization at our center for repeat revascularization with either SVG graft failure or nontarget vessel disease. Among these five cases, a 79-year male patient was readmitted with acute myocardial infarction (AMI) 31 months after surgery; the venous grafts anastomosed to the obtuse marginal branch (OM) and posterior descending artery (PDA) had been occluded, while the LIMA + SVG to LAD segments were patent from the coronary angiography images (Figure 4).

\section{Discussion}

This single-center retrospective study of propensitymatched patients showed that early and mid-term outcomes of using LIMA + SVG composite graft to bypass the LAD when the in situ LIMA was unavailable were comparable to those of LIMA - LAD. These results demonstrate that this novel operation strategy is safe and feasible.

LIMA to LAD anastomosing has been the golden standard of CABG, and three major guidelines have recommended using LIMA to bypass the LAD (1,4,17-19). In some large randomized clinical trials, the rate of occurrence of unavailable LIMA from all causes was 4-9\% (20-22), which is similar to the $8.5 \%$ in our study. For the choice of alternative conduits, free IMA may be a suitable strategy. For outcomes of this strategy, Vistarini et al. (5) reported that in $94.1 \%$ of patients who used free LIMA conduits versus in situ LIMA - LAD, free IMA to bypass LAD did not increase operative mortality or major postoperative adverse events in long-term follow-up. However, free LIMA was not suitable for most of the cases in our center, and extra free right internal mammary artery (RIMA) harvesting may increase the risk of deep sternal wound infection, especially for patients with diabetes for whom this risk can reach upwards of $11 \%$ (23). Our strategy did not increase the incidence rate of deep sternal wound infection $(1.2 \%)$, despite the population having a mean age of 66.1 years and a $44.6 \%$ rate of diabetes. Analogically, radial arteries (RA) have been shown to have better longterm outcomes and patency than SVG when anastomosed to the non-LAD territories (24). However, they are sensitive to competitive flow, and using the RA is recommended only for target vessels with a high-degree of stenosis $(18,25,26)$, or if the availability to the LAD is unknown.

Using an arterial-venous composite is the standard 

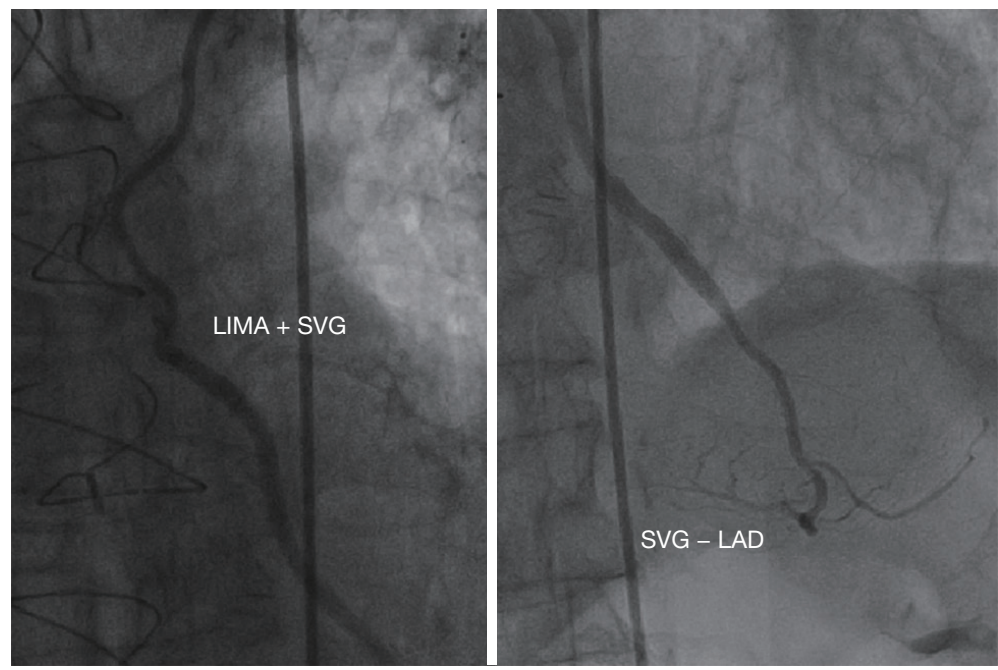

Figure 4 CAG images of the LIMA + SVG segment and SVG-LAD segment. CAG images show that the LIMA + SVG to bypass the LAD segments were patent 31 months after surgery. CAG, coronary angiography; LIMA, left internal mammary artery; SVG, great saphenous vein graft; LAD, left anterior descending artery.

CABG procedure proposed by Kim et al. (27) In this approach, the arterio-venous (LIMA + SVG) anastomosis is constructed as a $\mathrm{Y}$ or $\mathrm{T}$ graft, and the venous segment is used to revascularize the lateral and inferior walls. Their results showed that the saphenous vein composite grafts were noninferior to RIMA composite grafts in terms of 5 -year graft occlusion rates and midterm clinical outcomes. In our study, LIMA + SVG was anastomosed end-to-end and was used to revascularize the LAD as a bail-out. Otherwise, the superior patency rate of SVG to bypass LAD compared with other territories has been proven by Goldman (2), and thus was the rational theoretical basis for our strategy.

In our practice, two factors determine the length of the SVG: one, the length of the distal LIMA to be cut off to obtain satisfactory blood flow; two, the sufficient length of the LIMA + SVG graft to bypass the LAD lesion. In the present study, the mean length of the SVG segment was $3.9 \pm 1.8 \mathrm{~cm}$ (range, $3-6 \mathrm{~cm}$ ). If the SVG was too long or too short, other strategies were considered. A critical point is the diameter matching between the arterial and venous conduits, we chose the SVG of the distal end of the lower leg and reduced distension to guarantee diameter matching with the LIMA. In most cases in this study, the LIMA and SVG were well matched. However, in rare cases, the size of SVG was not the same as that of the LIMA graft, therefore, we had performed aorta (AO)-SVG-LAD anastomosis in these cases, which were excluded from this study.

For CABG strategy choice, most of the patients received off-pump CABG to reduce aorta manipulation and lower the complications related to cardiopulmonary bypass (CPB). We chose the on-pump CABG in the following highrisk situations: LVEF less than 35\%, left ventricular enddiastolic diameter (LVDD) greater than $65 \mathrm{~mm}$, expected hemodynamic instability, complex anatomy of the target vessel unsuitable for off-pump CABG. These off-pump procedures used the in situ LIMA as much as possible to reduce the manipulation of a diseased aorta, which could decrease the incidence rate of postoperative stroke (28). In this study, the rate of postoperative stroke was $1.2 \%$, which was comparable with a previously reported $1-3 \%$ rate (29). Kaplan-Meier survival analysis indicated that the estimated 5 -year postoperative mid-term mortality and incidence of MACCE in the LIMA + SVG group was $4.9 \%$ and $14.9 \%$, respectively. These results are comparable to those yielded in the 5-year follow-ups of large, contemporary CABG trials with rates ranging from $5 \%$ to $15 \%$, and $13 \%$ to $27 \%$, respectively (30-32). Additionally, we obtained an outstanding patency rate (94\%) 25 months after the procedure, which was equivalent to that achieved by LIMA - LAD (95\% at 1 year) in large, contemporary CABG trials (25).

These satisfactory outcomes may be due to the following advantages of our surgical strategy. (I) Our surgical procedures use in situ LIMA to connect with the SVG instead of an aortocoronary bypass graft with free IMA or SVG. This measure can reduce the mismatching between the thickness of the vascular wall of the aorta and the IMA. 
(II) Biologically speaking, nitric oxide (NO) is a well-known vasodilator and antiatherosclerotic substance of endothelial origin. The LIMA graft provides beneficial metabolic effects not only in the graft itself but also for the recipient downstream artery via its superior NO secretion. Our LIMA + SVG strategy preserves the in situ LIMA as much as possible, which may help the downstream SVG and target vessels. Physical damage to the endothelial layer also occurs while preparing a graft by high-pressure dilation of the SVG; we reduce distension when harvesting the SVG, which may decrease the degenerative and atherosclerotic processes of SVG (33). (III) Anastomoses can be performed more easily, quickly, and effectively compared with a direct LIMA anastomosis. (IV) We use the SVG from a lower leg segment to reduce the potential possibility of vascular diameter mismatching with the LIMA or LAD. (V) Our positive education on long-term secondary prophylactic medication compliance might also contribute to the comparable results.

There have been many exciting developments in surgical technology that have reduced the invasiveness of CABG, including minimally invasive direct coronary artery bypass (MIDCAB), robotic CABG, and hybrid coronary revascularization (HCR), the latter of which has received particular attention in recent years (29). All these alternative procedural approaches to a sternotomy for CABG may be performed via a small left anterior thoracotomy. When facing an unavailable LIMA in these procedures, surgeons might choose conversion to sternotomy. However, our strategy of using the LIMA + SVG to bypass the LAD might be a better, even faultless way to avoid conversion to sternotomy, and may have other valuable applications.

However, several limitations should be noted regarding this retrospective single-center study. (I) Despite the benefits of propensity score matching, the non-randomized design might have affected our results. (II) Although our study is the most extensive research of LIMA + SVG to bypass $\mathrm{LAD}$ to be conducted thus far, the sample size was still small due to the low incidence of unavailable in situ LIMA and the preference of surgeons. Further verification of the clinical effect of this strategy requires a greater accumulation of cases. (III) Finally, there was a lack of complete imaging follow-up data to compare the mid- and long-term graft patency between the two groups.

\section{Conclusions}

Our single-center propensity score-matching analysis study is the most thorough examination of LIMA + SVG to bypass LAD to have thus far been conducted. Our findings indicate that this approach achieved comparable early and mid-term outcomes to those of LIMA - LAD. Therefore, using the in situ LIMA with SVG to revascularize the LAD may supply an alternative emergency strategy when in situ LIMA is unable to bypass the LAD. Further study needs to be conducted to evaluate longer-term outcomes.

\section{Acknowledgments}

Funding: None.

\section{Footnote}

Reporting Checklist: The authors have completed the STROBE reporting checklist. Available at http://dx.doi. org/10.21037/jtd-20-2358

Data Sharing Statement: Available at http://dx.doi. org/10.21037/jtd-20-2358

Conflicts of Interest: All authors have completed the ICMJE uniform disclosure form (available at http://dx.doi. org/10.21037/jtd-20-2358). The authors have no conflicts of interest to declare.

Ethical Statement: The authors are accountable for all aspects of the work in ensuring that questions related to the accuracy or integrity of any part of the work are appropriately investigated and resolved. The study was conducted in accordance with the Declaration of Helsinki (as revised in 2013). The study was approved by local research ethics board of Chaoyang Hospital (No.: 2018308) and individual consent for this retrospective analysis was waived.

Open Access Statement: This is an Open Access article distributed in accordance with the Creative Commons Attribution-NonCommercial-NoDerivs 4.0 International License (CC BY-NC-ND 4.0), which permits the noncommercial replication and distribution of the article with the strict proviso that no changes or edits are made and the original work is properly cited (including links to both the formal publication through the relevant DOI and the license). See: https://creativecommons.org/licenses/by-nc-nd/4.0/.

\section{References}

1. Loop F, Lytle B, Cosgrove D, et al. Influence of the 
internal-mammary-artery graft on 10-year survival and other cardiac events. N Engl J Med 1986;314:1-6.

2. Goldman S, Zadina K, Moritz T, et al. Long-term patency of saphenous vein and left internal mammary artery grafts after coronary artery bypass surgery: results from a Department of Veterans Affairs Cooperative Study. J Am Coll Cardiol 2004;44:2149-56.

3. Shah PJ, Durairaj M, Gordon I, et al. Factors affecting patency of internal thoracic artery graft: clinical and angiographic study in 1434 symptomatic patients operated between 1982 and 2002. Eur J Cardiothorac Surg 2004;26:118-24.

4. Zeff RH, Kongtahworn C, Iannone LA, et al. Internal mammary artery versus saphenous vein graft to the left anterior descending coronary artery: prospective randomized study with 10-year follow-up. Ann Thorac Surg 1988;45:533-6.

5. Vistarini N, Kalavrouziotis D, Dagenais F, et al. Does the use of a free internal mammary artery graft on the left anterior descending artery compromise long-term survival? Eur J Cardiothorac Surg 2017;52:753-9.

6. Saito A, Miyata H, Motomura N, et al. Propensitymatched analysis of bilateral internal mammary artery vs single internal mammary artery in 7702 cases of isolated coronary artery bypass grafting. Eur J Cardiothorac Surg 2013;44:711-7.

7. Buttar SN, Yan TD, Taggart DP, et al. Long-term and short-term outcomes of using bilateral internal mammary artery grafting versus left internal mammary artery grafting: a meta-analysis. Heart 2017;103:1419-26.

8. Taggart DP, Altman DG, Gray AM, et al. Randomized Trial of Bilateral versus Single Internal-Thoracic-Artery Grafts. N Engl J Med 2016;375:2540-9.

9. Ji Q, Mei Y, Wang X, et al. Impact of diabetes mellitus on old patients undergoing coronary artery bypass grafting. Int Heart J 2009; 50:693-700.

10. Tremblay JA, Stevens LM, Chartrand-Lefebvre C, et al. A novel composite coronary bypass graft strategy: the saphenous vein bridge--a pilot study. Eur J Cardiothorac Surg 2013;44:e302-7.

11. Kim YH, Oh HC, Choi JW, et al. No-Touch Saphenous Vein Harvesting May Improve Further the Patency of Saphenous Vein Composite Grafts: Early Outcomes and 1-Year Angiographic Results. Ann Thorac Surg 2017;103:1489-97.

12. Cannon CP, Brindis RG, Chaitman BR, et al. 2013 ACCF/ AHA key data elements and definitions for measuring the clinical management and outcomes of patients with acute coronary syndromes and coronary artery disease: a report of the American College of Cardiology Foundation/ American Heart Association Task Force on clinical data standards (writing committee to develop acute coronary syndromes and coronary artery disease clinical data standards). J Am Coll Cardiol 2013;61:992-1025.

13. Serruys PW, Morice MC, Kappetein AP, et al.

Percutaneous coronary intervention versus coronary-artery bypass grafting for severe coronary artery disease. N Engl J Med 2009;360:961-72.

14. Su P, Gu S, Liu Y, et al. Off-Pump Coronary Artery Bypass Grafting with Mini-Sternotomy in the Treatment of Triple-Vessel Coronary Artery Disease. Int Heart J 2018;59:474-81.

15. Novitzky D, Shroyer A, Collins J, et al. A study design to assess the safety and efficacy of on-pump versus off-pump coronary bypass grafting: the ROOBY trial. Clin Trials 2007;4:81-91.

16. Normand ST, Landrum MB, Guadagnoli E, et al. Validating recommendations for coronary angiography following acute myocardial infarction in the elderly: a matched analysis using propensity scores. J Clin Epidemiol 2001;54:387-98.

17. Hillis LD, Smith PK, Anderson JL, et al. 2011 ACCF/ AHA Guideline for Coronary Artery Bypass Graft Surgery: a report of the American College of Cardiology Foundation/American Heart Association Task Force on Practice Guidelines. Circulation 2011;124:e652-735.

18. Windecker S, Kolh P, Alfonso F, et al. 2014 ESC/EACTS Guidelines on myocardial revascularization: The Task Force on Myocardial Revascularization of the European Society of Cardiology (ESC) and the European Association for Cardio-Thoracic Surgery (EACTS) Developed with the special contribution of the European Association of Percutaneous Cardiovascular Interventions (EAPCI). Eur Heart J 2014;35:2541-619.

19. Aldea GS, Bakaeen FG, Pal J, et al. The Society of Thoracic Surgeons Clinical Practice Guidelines on Arterial Conduits for Coronary Artery Bypass Grafting. Ann Thorac Surg 2016;101:801-9.

20. Farkouh ME, Domanski M, Sleeper LA, et al. Strategies for multivessel revascularization in patients with diabetes. N Engl J Med 2012;367:2375-84.

21. Hattler B, Messenger JC, Shroyer AL, et al. Off-Pump coronary artery bypass surgery is associated with worse arterial and saphenous vein graft patency and less effective revascularization: Results from the Veterans Affairs Randomized On/Off Bypass (ROOBY) trial. Circulation 


$$
\text { 2012;125:2827-35. }
$$

22. Zhao Q, Zhu Y, Xu Z, et al. Effect of Ticagrelor Plus Aspirin, Ticagrelor Alone, or Aspirin Alone on Saphenous Vein Graft Patency 1 Year After Coronary Artery Bypass Grafting: A Randomized Clinical Trial. JAMA 2018;319:1677-86.

23. Peterson MD, Borger MA, Rao V, et al. Skeletonization of bilateral internal thoracic artery grafts lowers the risk of sternal infection in patients with diabetes. J Thorac Cardiovasc Surg 2003;126:1314-9.

24. Gaudino M, Benedetto U, Fremes S, et al. Radial-Artery or Saphenous-Vein Grafts in Coronary-Artery Bypass Surgery. N Engl J Med 2018;378:2069-77.

25. Desai ND, Cohen EA, Naylor CD, et al. A randomized comparison of radial-artery and saphenous-vein coronary bypass grafts. N Engl J Med 2004;351:2302-9.

26. Buxton BF, Hayward PAR, Newcomb AE, et al. Choice of conduits for coronary artery bypass grafting: craft or science? Eur J Cardiothorac Surg 2009;35:658-70.

27. Kim MS, Hwang HY, Kim JS, et al. Saphenous vein versus right internal thoracic artery as a Y-composite graft: Fiveyear angiographic and clinical results of a randomized trial. J Thorac Cardiovasc Surg 2018;156:1424-33.e1.

Cite this article as: Li D, Gu S, Liu Y, Zhang X, An X, Yan J, Wang H, Guo Y, Su P. Outcomes of left internal mammary artery with saphenous vein composite graft to bypass the left anterior descending artery: a propensity-matched study. J Thorac Dis 2020;12(11):6629-6639. doi: 10.21037/jtd-20-2358
28. Zhao DF, Edelman JJ, Seco M, et al. Coronary Artery Bypass Grafting With and Without Manipulation of the Ascending Aorta: A Network Meta-Analysis. J Am Coll Cardiol 2017;69:924-36.

29. Head SJ, Milojevic M, Taggart DP, et al. Current Practice of State-of-the-Art Surgical Coronary Revascularization. Circulation 2017;136:1331-45.

30. Alexander JH, Hafley G, Harrington RA, et al. Efficacy and safety of edifoligide, an E2F transcription factor decoy, for prevention of vein graft failure following coronary artery bypass graft surgery: PREVENT IV: a randomized controlled trial. JAMA 2005;294:2446-54.

31. Lamy A, Devereaux P, Prabhakaran D, et al. Five-Year Outcomes after Off-Pump or On-Pump Coronary-Artery Bypass Grafting. N Engl J Med 2016;375:2359-68.

32. Mohr FW, Morice MC, Kappetein AP, et al. Coronary artery bypass graft surgery versus percutaneous coronary intervention in patients with three-vessel disease and left main coronary disease: 5-year follow-up of the randomised, clinical SYNTAX trial. Lancet 2013;381:629-38.

33. Kitamura S. Physiological and metabolic effects of grafts in coronary artery bypass surgery. Circ J 2011;75:766-72. 